\title{
STRESS AT WORK
}

\author{
Julia von Onciul
}

\section{Adaptation to the workplace and general adaptation syndrome}

Changes in the work environment have led to a change in the balance between physical and mental activity. Technological developments have reduced the amount of heavy physical work. Mental and emotional

General adaptation syndrome

1 Alarm reaction

2 Resistance stage

3 Exhaustion stage strain have increased in new working environments that are characterised by lack of time, more uncontrollable factors, background distractions, lack of space, general uncertainty, and more administrative work. The general adaptation syndrome, described by the physiologist Selye in 1975, characterises the process of prolonged exposure to stress and is a useful staged concept.

$\begin{array}{ll}\text { Work related stressors } & \\ \text { Physical stressors } & \text { Emotional and mental stressors } \\ \text { - Noise } & \text { - Fear (of sanctions) } \\ \text { - Chemical hazards } & \text { - Joy (about promotion) } \\ \text { - Temperature extremes } & \text { - Anger (over injustice) } \\ \text { - Physical trauma } & \text { - Challenge (of a new position) } \\ \text { - Radiation } & \text { - Shock (after sexual harassment or racial taunt) } \\ \text { - Poor posture } & \text { - Competition (with colleague) } \\ \text { - Vibration } & \text { - Conflicts (with subordinates or managers) } \\ \text { - Handling of heavy goods } & \text { - Contradictory instructions } \\ \text { - Monotonous tasks } & \text { - Negative thoughts } \\ \text { - Night shifts } & \text { - Time pressure } \\ \text { - Overtime } & \text { - Structural changes } \\ & \text { - Monotonous tasks } \\ & \text { - Night shifts } \\ & \text { - Overtime }\end{array}$

Symptoms of the alarm reaction

- Palpitations-irregular or fast heart beats

- Shallow, fast breathing

- Muscle tension-especially lower back, neck

and shoulders

- Dryness of the throat

- Nausea

- Anxiety

- Dizziness and lightheadedness

- Sweating

- Numbness of the limbs

\begin{tabular}{|c|c|c|}
\hline \multicolumn{3}{|c|}{$\begin{array}{l}\text { Examples of coping strategies } \\
\text { Perceived psychological stressor: conflict with manager }\end{array}$} \\
\hline $\begin{array}{l}\text { Coping strategy } \\
\text { Short term effect }\end{array}$ & $\begin{array}{l}\text { Adequate method } \\
\text { Talk about issue assertively } \\
\text { Negative-Feeling } \\
\text { uncomfortable }\end{array}$ & $\begin{array}{l}\text { Inadequate method } \\
\text { Start heavy drinking } \\
\text { Positive-Relaxation }\end{array}$ \\
\hline Long term effect & $\begin{array}{l}\text { Positive-Self confidence } \\
\text { improves }\end{array}$ & $\begin{array}{l}\text { Negative-Secondary } \\
\text { problems from alcohol } \\
\text { misuse, reduced } \\
\text { performance }\end{array}$ \\
\hline \multicolumn{3}{|c|}{ Perceived physical stressor: constant heavy lifting by geriatric nurse } \\
\hline $\begin{array}{l}\text { Coping strategy } \\
\text { Short term effect }\end{array}$ & $\begin{array}{l}\text { Adequate method } \\
\text { Plan lifts, use aids } \\
\text { Negative-Taking more } \\
\text { time }\end{array}$ & $\begin{array}{l}\text { Inadequate method } \\
\text { Take time off with bad back } \\
\text { Positive-Back strain } \\
\text { improves }\end{array}$ \\
\hline Long term effect & $\begin{array}{l}\text { Positive-Less backache, } \\
\text { self confidence improves }\end{array}$ & $\begin{array}{l}\text { Negative-Possibility of } \\
\text { losing job (too much time off) }\end{array}$ \\
\hline
\end{tabular}

\section{Alarm reaction} activities.

\section{What triggers work stress?}

Stressors are the agents which trigger the various stress reactions. Today's environment provides physical, emotional, and mental stressors that set off the initial alarm reaction. Physical stressors in factories are usually linked to noise and physical and chemical hazards. Emotional or mental stressors can be unpleasant or pleasant. A promotion can be just as stressful as the loss of a position.

Stressors are additive and can build up. The way in which people are affected depends on their values, experience, and adaptability. A single stressor can become compounded if elements of the established support system fail-for example, if a car breaks down on the way to an important meeting.

This is the immediate response to a challenge or threat. Mobilisation of the autonomic nervous system triggers the stress response ("fight or flight" response). The various body systems involved coordinate the readiness for action, influencing mood (limbic system), the regulation of the cardiovascular system, breathing, muscle tension, and fine motor

\section{Resistance stage}

The alarm reaction cannot be maintained indefinitely, and longer exposure to stressors causes people to reach the resistance stage. In this phase people develop a "survival" strategy and a way of fighting against the response the stressor has initiated.

Coping mechanisms may be adequate or inadequate. People tend to prefer short term relief to long term solutions and try to escape uncomfortable situations with a quick remedy. Unfortunately, most easy, short term measures are inadequate because they usually lead to secondary problems such as long term reduction in performance. People need help to identify measures that can lead to long term benefit. 


\section{Symptoms of exhaustion stage-}

\section{Physical disorders}

- Tensiol headaches, migraines

- Irritable bowel syndrome

- Impaired resistance-Colds and other "viral" illnesses

- Potentiation of asthma, dermatitis, psoriasis, backache

- "Gastritis"

- High blood pressure

- Work related upper limb disorder

\section{Exhaustion stage}

The stress response is healthy in origin and is necessary to keep a person motivated and adaptable. It is when the demands on body and mind are too high or cannot be met in an appropriate way that the person becomes "distressed." Prolonged stress can lead to chronic problems, ultimately an exhaustion of all reserves and energies and even frank depression.

Physical symptoms of impending exhaustion may present with a general feeling of tiredness, lack of energy, and weakness. Non-specific signs can be visual blurring, dizziness, chest tightness, discomfort in breathing, and gastrointestinal symptoms ranging from chronic constipation to diarrhoea and cramps. Sleeping patterns may be disturbed, with difficulty in getting off to sleep and early morning waking accompanied by nightmares. Weight gain or loss is common. Changes in eating patterns range from lack of appetite to overeating or indulging in chocolates. In the workplace people may be able to hide their symptoms unless they become overwhelming, in which case absence from work ensues and the problems present elsewhere (at home or in the doctor's surgery).

Emotional symptoms of stress in the exhaustion stage relate to depression and frustration. These may be manifested in uncontrollable crying; lack of interest in friends, hobbies, and family; and general indifference and reduced attention to personal issues such as exercise, clothes, and eating. In extreme cases self destructive and suicidal tendencies are present. Irritability, coldness, and harshness towards others are often accompanied by extreme guilt. Panic attacks and restlessness can make work difficult and increase stress at work as they are more apparent to colleagues.

Mental dysfunction in the exhaustion stage presents as a lack of concentration and coordination. This leads to impaired performance and judgment as well as a negative attitude towards work and indecisiveness. In the workplace signs of mental dysfunction are usually noticed more easily than signs of physical illness because they are directly related to performance and thus more apparent to colleagues. The resulting loss of confidence and control disturbs the individual, further reducing performance. Misuse of alcohol, cigarettes, tranquillisers, and other drugs is often observed.

Burnout - This term describes the emotional and psychological results of long continued stress and is based on studies of the social professions, teachers, social workers, and medical staff. Idealistic enthusiasm, conflicting roles, and extreme commitment are typical starting points for the development of this condition, in which mental and emotional exhaustion ultimately lead to apathy and revulsion against everything and everybody.

Post-traumatic stress disorder is a specific form of anxiety disorder following exposure to an extraordinary stressor outside the usual realm of human experience (such as witnessing an armed robbery or fatal accident at work). Subacute or chronic, it is characterised by intrusive psychological re-experiencing of the traumatic event, mental numbness, and symptoms of increased arousal. Emergency services and organisations that experience traumatic incidents (such as intensive care units, banks) often use post-traumatic stress debriefing techniques to prevent development of the disorder. However, their value has not yet been proved. Established post-traumatic stress disorder needs specialised help.
Members of the emergency services are at particular risk of post-traumatic stress disorder.

\section{Individual susceptibility to stress}

\author{
Factors affecting individual \\ susceptibility to stress \\ - Individual constitution \\ - Lifestyle and work style \\ - Coping mechanisms \\ - Emotional stability \\ - Previous experiences \\ - Expectation \\ - Self confidence
}

The amount of stress experienced by a person depends on various factors. Heredity plays a role in determining the type of autonomic response and which organ systems will be affected. Other factors are related to lifestyle-such as sleeping and eating habits and behavioural type. The reaction to stress will depend on what strategies are available to the individual - such as relaxation techniques and finding a balance. Work style, organisational skills, attitude towards unpredictable and difficult situations, trust in own abilities, handling of traumatic situations, and "luck" will also determine a person's susceptibility to stress at work. 


\section{Factors in the working environment that affect stress}

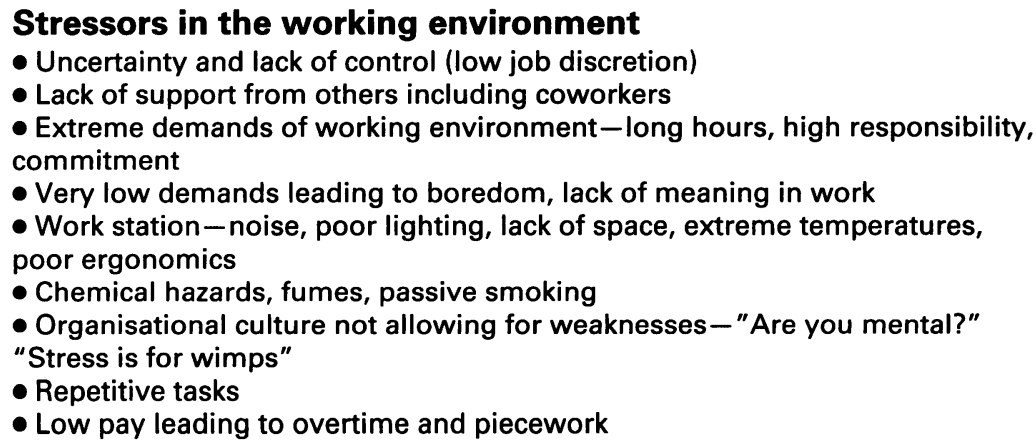

- Uncertainty and lack of control (low job discretion)

- Lack of support from others including coworkers

- Extreme demands of working environment-long hours, high responsibility, commitment

- Very low demands leading to boredom, lack of meaning in work

- Work station-noise, poor lighting, lack of space, extreme temperatures,

poor ergonomics

- Chemical hazards, fumes, passive smoking

- Organisational culture not allowing for weaknesses - "Are you mental?"

"Stress is for wimps"

- Repetitive tasks

- Low pay leading to overtime and piecework

Stress is often related directly to the job specifications and working environment or to relationships with people at work, or a combination of both. Conflicts with managers, subordinates, or colleagues may increase as work becomes more pressured. Smaller workforces are expected to do the same or more work, and there is a widespread lack of training in communication and interpersonal skills.

Some of the stress also relates to the identification of a person's role-is the person being asked to be a director or team player? Dissatisfaction is often linked to a lack of autonomy and control in a job.

\section{Dealing with stress}

\author{
Difficulties in exploring stress at work \\ - Patient refuses to relate symptoms to work \\ stress \\ - Patient refuses to accept that own behaviour is \\ counterproductive \\ - Insufficient information retrievable \\ - Other people blamed \\ - Non-specific symptoms \\ - Long history of illness
}

\section{Exploring work related stress}

Ask questions about the following topics

- Recent restructuring in working environment

- Description of workplace

- Particular worries, especially interpersonal

- Timing of symptoms in relation to stressors

- Increase in substance misuse

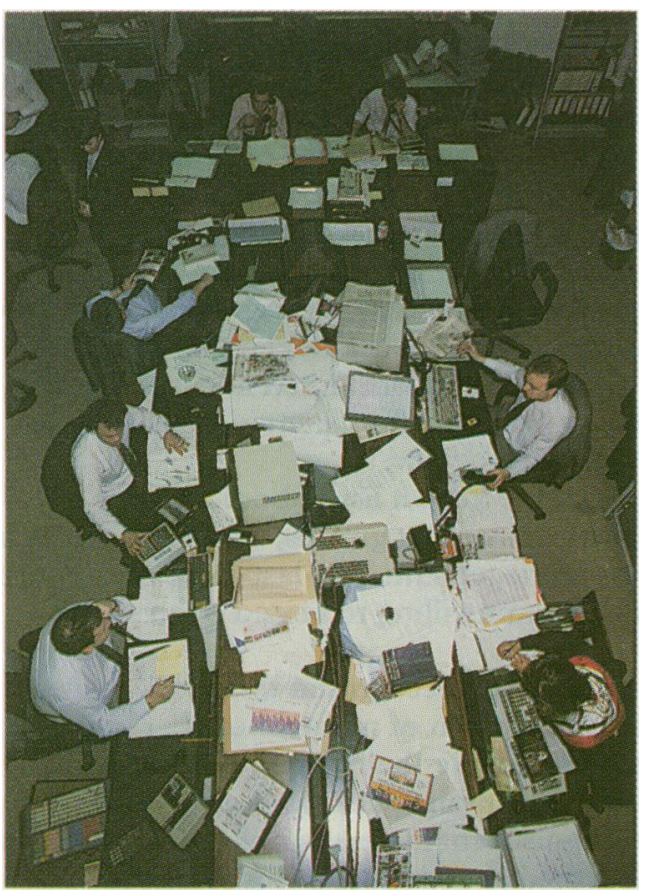

A person's working environment determines what types of stressor he or she may encounter.

\section{Doctor's role}

The extent of stress at work and its implications are often difficult to investigate and delineate. This is especially so if the symptoms are primarily attributed to a physical condition - for example, headaches ("high blood pressure"), overeating ("obesity in the family"), backache ("scoliosis"). Patients themselves may not want to recognise the presence of stress. For example, those with "type A" personalities often demand a quick, functional, and "easy" remedy for their discomfort, expecting their doctor to miraculously abolish their symptoms.

Information about the working environment may be lacking, either because it is complex-such as a clean room in microchip productionor because of a patient's lack of insight into possible factors in the workplace. It may be difficult to establish whether stress is the result or the cause of a problem at work. Stress may also be part of a wider picture and due to problems outside the working environment-thus, underlying problems in the family or social environment may manifest themselves in stress at work.

If a patient has longstanding stress it may be difficult to trace the origin and trigger of the symptoms. Inquiries about early signs (alarm reaction) can help to identify the start of the problems. With patients who have recently developed symptoms of stress, a few direct questions can indicate a relation to the working environment. Such questioning may help to identify situations that are likely to improve shortly or long term problems that may need closer attention and further investigation.

The root of stress at work may be major changes in the organisation such as new systems of work or problematic colleagues or managers. Impending redundancies, an important deal to close, or an unwanted transfer to a new position can be reasons for worrying. Ask the patient to give a brief description of the work environment-such as factory floor versus office. This may give a clue to the type of stressor encountered-such as noise versus pressure to negotiate a deal. Ask about symptoms occurring typically days before or after a work related stress-a "viral" infection three days after an important meeting, a headache before going to work in the morning or on weekends after a particularly stressful week.

Prescribing drugs-Tranquillisers and $\beta$ blockers are popular for short term relief of stress but can be disastrous in the long term because of the risks of dependency with tranquillisers and myocardial depression with $\beta$ blockers. More importantly, they do not treat the root of the problem. For the same reason, antidepressants are not advisable for long term treatment. 


\section{Courses that may help to reduce stress at work}

- Desk and time management

- Prioritising

- Handling meetings and

presentations

- Assertiveness

\section{Practical self management for stressed patients}

- Take exercise-three 20 minute sessions a week recommended

- Improve posture

- Healthy eating

Arrange to meet friends to go out for lunch

the evening

Eat and drink less at business meetings

Keep soft drinks or water readily available at work

- Stop smoking and drinking alcohol

- Talk to others, such as friends or family

- Listen to tapes and read books

- Take up relaxing hobbies - such as painting but not motor racing
Take prepared snacks to work instead of starving all day and overeating in

\section{Patient's role}

Stress management requires the patient's cooperation and active participation. There are psychological implications, and the patient must take responsibility for his or her actions, thinking about solutions and most probably changing behaviour.

Stress management involves:

- External changes-that is, in lifestyle and working environment

- Internal changes - in behaviour and perception, and in biological response.

Main strategies for reducing work stress include:

- Optimising the workplace where possible and required-get help from an occupational health specialist

- Balancing work stress with a healthy lifestyle and relaxing activities

- Changing personal and work attitude and behaviour where necessary-start with small changes.

\section{Relaxation techniques}

- Progressive muscle relaxation (such as Jacobsen technique)-easy to learn, flexible in time (sessions can last 1-30 minutes), can be used almost anywhere and any time

- Transcendental meditation-develops feelings of refreshment and vitality,

10-1.5 minutes a day

- Autogenic training-mental circuit training, 10-15 minutes a day

- Alexander technique - reduces lower back pain and tension in shoulder and neck, usually 20 sessions needed to obtain long term benefit

- Martial arts - reduction of tensions through controlled movements (not at work)

- Yoga-fairly complicated technique, experience needed, not usually a short term solution but helpful for some

- Autosuggestion - after initial training applicable to reducing stress before important meetings, etc, but also to reducing addictive behaviour; often needs to be accompanied by other techniques; danger of not treating underlying causes

\section{Relaxation at work:}

- Some techniques are easy to use in a working environment

- Small, frequent breaks (for five minutes every hour) are more relaxing than fewer, longer breaks (for one hour after four hours of continuous work)

- Small physical exercises are useful for computer users

- A few deep breaths with slow exhaling can counteract an immediate stress reaction or panic attack

- Make use of available courses run by psychologists.

\section{Cooperation in managing stress}

\author{
Multidisciplinary approach to \\ treatment \\ - Occupational health departments \\ - Psychotherapy \\ - Support groups \\ Alternative medicine \\ - Physiotherapy \\ - Relaxation therapy \\ - Management training \\ - Counselling
}

\begin{abstract}
The photographs of police and stockbrokers were taken by Norman Lomax and Ben Edwards respectively and were reproduced with permission of Impact.
\end{abstract}

Julia von Onciul is a senior manager of LucasVarity Industries Management Development and Training Department, Solihull, and is a former occupational health physician for IBM Germany.

The ABC of Work Related Disorders is edited by David Snashall, clinical director of Occupational Health Services, Guys and St Thomas's Hospitals NHS Trust, London.
Most workplaces do not employ occupational health staff, but if they do so it is useful to liaise with them as they may be aware of a broader problem affecting several employees and may already be implementing remedial action. There may be an easy solution. An occupational health professional may only take an hour to find out the origin of a problem which resulted in an employee's absence from work.

Counselling-Patients can be advised to attend confidential, non-judgmental counselling over several weeks, in a group or individual setting and usually in one hourly session a week depending on need.

Psychological treatment - This should be considered in cases where there is a fundamental psychological issue: for example, a serious lack of interpersonal skills or addictive behaviour.

Other support groups-It is useful to keep a list of bodies and organisations that provide names of support groups, training courses on relaxation, and books on stress management. The last form of support may be a tool for the patient who is unwilling to attend open group discussions.

Recognition - The English courts have recognised that work related stressors can contribute to the breakdown of mental health, reminding employers that they have a duty to ensure their employees' psychological health as well as their physical health. Patients will appreciate it if their doctor recognises that stress is ubiquitous, affecting many people, but allowing of remedial action. It is important to take away the feelings of stigma and failure that often obsess patients with stress symptoms and which lead to an increase in their pressure levels. 